\title{
Neuroradiological Manifestations of Hereditary Hemorrhagic Telangiectasia in 139 Japanese Patients
}

\author{
Masaki KomiYAmA, ${ }^{1}$ Aiko Terada, ${ }^{1}$ Tomoya Ishiguro, ${ }^{1}$ Yusuke WATANABE, ${ }^{2}$ \\ Hideki NAKAJIMA, ${ }^{2}$ Osamu YAMADA, ${ }^{3}$ and Hiroko MORISAKI ${ }^{4}$
}

\author{
Departments of ${ }^{1}$ Neuro-intervention and ${ }^{2}$ Neurosurgery, Osaka City General Hospital, \\ Osaka, Osaka; \\ Departments of ${ }^{3}$ Pediatric Cardiology and ${ }^{4}$ Bioscience and Genetics, National Cerebral \\ and Cardiovascular Center, Suita, Osaka
}

\begin{abstract}
The purpose of this study is to report the neuroradiological manifestations of hereditary hemorrhagic telangiectasia (HHT). One hundred and thirty-nine Japanese HHT patients (73 men and 66 women, aged 2-78 years) were included in this study. Diagnosis of HHT was based on genetic analysis and/or clinical diagnosis of Curaçao. They included 68 HHT1 and 37 HHT2 patients. Essentially, all patients underwent brain magnetic resonance imaging (MRI) and pulmonary computed tomography (CT). Contrast enhanced studies of brain MRI and hepatic CT were performed in a subset of patients. Catheter cerebral angiography was performed when indicated. Their neuroradiological features were reviewed retrospectively. Various imaging abnormalities were found. Brain arteriovenous malformations (AVMs) were observed in $27 / 136$ patients $(19.9 \%, 21$ patients with HHT1 and 1 patient with HHT2). Pulmonary arteriovenous fistulas (AVFs) were found in 73/137 patients (65.2\%, 45 patients with HHT1 and 6 patients with HHT2). Cerebral infarction and brain abscess were found in 17 patients and 3 patients with pulmonary AVFs, respectively. T1 high lesions in the basal ganglia suggestive of porto-venous shunts were observed in $51 / 136$ patients (37.5\%, 9 patients with HHT1 and 28 patients with HHT2). Hepatic AVMs were observed in 61/136 patients $(44.9 \%, 15$ patients in HHT1 and 29 patients in HHT2). Brain AVMs and pulmonary AVFs were more common in HHT1 than in HHT2 (both $p<0.01$ ), but hepatic AVMs were conversely more common in HHT2 than in HHT1 $(p<0.01)$. In conclusion, HHT patients present with a variety of neuroradiological manifestations, which are related to substantial causes of morbid-mortality in HHT.
\end{abstract}

Key words: brain arteriovenous malformation, hereditary hemorrhagic telangiectasia, magnetic resonance imaging, neuroradiological manifestation, pulmonary arteriovenous fistula

\section{Introduction}

Hereditary hemorrhagic telangiectasia (HHT) is inherited in the autosomal dominant manner, and its incidence is reported as approximately 1 in $5,000-8,000 .^{1,2)}$ HHT produces a variety of vascular lesions in many organs, including skin and mucosa, gastrointestinal tract, lung, liver, brain, and spinal cord..$^{3,4)}$ Among them, brain arteriovenous malformations (AVMs) and pulmonary arteriovenous fistulas (AVFs) are the main causes of substantial morbidity and mortality. Clinical diagnosis of HHT is usually based on the Curaçao criteria. ${ }^{5)}$ Two gene mutations; that is, mutations of endoglin (ENG) at chromosome $9 \mathrm{q} 34.1^{6-8)}$ and activin A receptor

Received February 13, 2015; Accepted March 11, 2015 type II-like 1 (ACVRL1) at chromosome 12q319,10) are known to produce HHT1 and HHT2, respectively. In addition to $E N G$ and $A C V R L 1$ genes, mutation of SMAD family member 4 (SMAD4) gene is related to a combined syndrome of HHT and juvenile polyposis. ${ }^{11)}$ Genotype-phenotype correlations have been reported mostly from North America and Europe. ${ }^{12,13)}$

Although neuroradiological features of HHT in the large series are reported from several HHT centers, ${ }^{14-17)}$ their diagnoses of HHT were mostly based on Curaçao criteria. Thus correlation between genotype and neuroradiological features are not clearly understood. Furthermore, there has been no report on $\mathrm{T}_{1}$ high lesions in the basal ganglia on magnetic resonance (MR) imaging suggestive of port-venous shunts in HHT in a large series. 
The purpose of this study is to report neuroradiological manifestations in HHT patients and genotypeneuroradiological phenotype correlations for better understanding of the diverse presentations of HHT in the largest Japanese cohort.

\section{Materials and Methods}

One hundred and thirty-nine Japanese HHT consecutive patients (73 men and 66 women, aged 2-78 years with a mean of 40.1 years) were included in this study. They were evaluated at the HHT center in Osaka City General Hospital, Osaka, Japan, during the past 10 years. Age of the patients was timing when they visited us for the first time. Diagnosis of HHT of these patients was established on either genetic analysis (105 patients) and/or clinical "definite" diagnosis of Curaçao criteria (34 patients). ${ }^{5}$

$E N D$ and $A C V R L 1$ gene mutations were first investigated. When END and ACVRL1 gene mutations were not detected, SMAD4 gene mutation was then investigated. The Curaçao diagnostic criteria are as follows: (a) spontaneous recurrent nosebleeds; (b) mucocutaneous telangiectasia at the characteristic sites (lips, tongue, fingertips, and so on); (c) visceral AVMs in lung, liver, brain, or spinal cord; and (d) affected patients in the first-degree relative according to these criteria. When the patients have more than three criteria, they are classified as "definite" HHT patients, and when two criteria are met, they are "probable." When one or no criterion is present, they are classified as "unlikely." According to the Curaçao criteria, 139 patients were classified as follows: 125 definite, 10 probable, and 4 unlikely HHT patients. Fourteen patients with either probable or unlikely diagnosis had either END or ACVRL1 gene mutations. Characteristics of the patients are listed in Table 1.

Among 139 patients, 118 patients underwent genetic analysis. There were 68 HHT1 patients (57.6\%, 38 men and 30 women with a mean age of 34.8 years, 34 kindred), 37 HHT2 patients (31.3\%, 17 men and 20 women with a mean age of 47.1 years, 23 kindred), and 13 patients with definite clinical diagnosis without identifiable gene $(11.0 \%$, 5 men and 8 women with a mean age of 45.9 years, 9 kindred). The remaining 21 patients were clinically definite HHT without genetic confirmation. SMAD4 gene mutation was not found in any patient.

Essentially, all patients except few pediatric patients underwent brain MR examination at 1.5 tesla or 3.0 tesla without contrast enhancement (136 patients) and X-ray CT of the lungs without contrast material (137 patients). Brain MR study usually included at least $\mathrm{T}_{1^{-}}$and $\mathrm{T}_{2}$-weighted images, fluid-attenuated inversion recovery (FLAIR) images, and time-offlight MR angiography. Slice thickness of lung CT was usually $3 \mathrm{~mm}$. Because many patients were referred from many hospitals where initial brain MR and lung CT studies were performed, scanning parameters of CT and MR examinations were variable. Contrast enhanced brain MR studies were

Table 1 Characteristics of 139 Japanese patients with hereditary hemorrhagic telangiectasia

\begin{tabular}{|c|c|c|c|c|c|c|}
\hline & \multicolumn{2}{|c|}{ Genetically HHT } & \multicolumn{2}{|c|}{ Clinically HHT } & \multirow[b]{2}{*}{ Total } & \multirow[b]{2}{*}{$p$-value } \\
\hline & HHT1 & HHT2 & NIM & $\begin{array}{l}\text { No genetic } \\
\text { confirmation }\end{array}$ & & \\
\hline No. of patients & 68 & 37 & 13 & 21 & 139 & \\
\hline Male/female & $38 / 30$ & $17 / 20$ & $5 / 8$ & $8 / 13$ & $68 / 71$ & \\
\hline Age & $2-78 / 34.8$ & $2-77 / 47.1$ & $12-70 / 45.9$ & $3-72 / 41.3$ & $2-78 / 40.1$ & $p<0.01$ \\
\hline Curaçao criteria & $60 / 6 / 2$ & $31 / 4 / 2$ & $13 / 0 / 0$ & $21 / 0 / 0$ & $125 / 10 / 4$ & \\
\hline Nose bleed & $65(95.6 \%)$ & $34(91.9 \%)$ & $12(92.3 \%)$ & $21(100 \%)$ & $132(95.0 \%)$ & $p=0.67$ (ns) \\
\hline Telangiectasia & $42(61.8 \%)$ & $30(81.1 \%)$ & $7(53.8 \%)$ & $13(61.9 \%)$ & $92(66.2 \%)$ & $p<0.05$ \\
\hline Family history & $64(94.1 \%)$ & $36(97.3 \%)$ & $13(100 \%)$ & $20(95.2 \%)$ & $133(95.7 \%)$ & $p=0.65$ (ns) \\
\hline Any visceral AVM & $57(83.8 \%)$ & $31(83.8 \%)$ & $12(92.3 \%)$ & $20(95.2 \%)$ & $120(86.3 \%)^{*}$ & \\
\hline Brain AVM & $21 / 66(31.8 \%)$ & $1 / 36(2.8 \%)$ & $0(0 \%)$ & $5(23.8 \%)$ & $27 / 136(19.9 \%)$ & $p<0.01$ \\
\hline Pulmonary AVF & $45 / 69(65.2 \%)$ & $6 / 36(16.7 \%)$ & $11(84.6 \%)$ & $11(52.4 \%)$ & $73 / 137(53.3 \%)$ & $p<0.01$ \\
\hline Hepatic AVM & 15/43 (34.9\%) & $29 / 34(85.3 \%)$ & $6(46.2 \%)$ & $11(52.4 \%)$ & $61 / 111(55.0 \%)$ & $p<0.01$ \\
\hline
\end{tabular}

*: pediatric patients were not always examined, age: age range/mean, AVF: arteriovenous fistula, AVM: arteriovenous malformation, Curaçao criteria: definite/probable/not likely, HHT: hereditary hemorrhagic telangiectasia, NIM: not identifiable mutation, $p$ : significant difference between HHT1 and HHT2. 
also performed in a subset of patients. Neuroradiological changes during follow-up periods among the limited number of the patients were also evaluated when the clinical and neuroradiological data were available. When brain MR examination showed either possible small AVMs or AVFs, the patients underwent digital subtraction angiography (DSA). Angiographic classification of brain AVMs were as follows: (a) micro-AVM with a lesion size less than $1 \mathrm{~cm}$; (b) small AVM with a nidus larger than $1 \mathrm{~cm}$ and smaller than $3 \mathrm{~cm}$; and (c) AVF with a direct arteriovenous (AV) shunt, according to the classification reported by Matsubara et al. ${ }^{18)}$ If a nidus of the AVM was larger than $3 \mathrm{~cm}$, this AVM was separately described. Three patients with AVMs had undergone surgical treatment before they came to us. Although they were evaluated again, available data on the removed lesions were added to the present study.

High intensity of the basal ganglia on $\mathrm{T}_{1}$-weighted MR images was interpreted to have porto-venous shunts in the liver when the intensity was obviously high in comparison to the surrounding brain structures and other etiologies to cause such high intensity lesions (chronic liver diseases, alcoholism, hepatitis, parenteral nutrition, and so on) were denied. Suspicious lesions with slightly $\mathrm{T}_{1}$ high intensity was not interpreted as high intensity lesions. In a subset of the patients with (22 patients) and without (12 patients) $\mathrm{T}_{1}$ high intensity lesions, serum manganese level was evaluated. Contrast enhanced and/or dynamic studies of the liver to detect AV and arterio-portal shunts were also performed in selected patients. The early filling of contrast material into the portal veins and/or hepatic veins was interpreted as the presence of arterio-portal and/or AV intrahepatic shunts.

The neuroradiological features, which include vascular malformations, vascular anomalies, cerebral aneurysms, parenchymal changes, cortical development, and $\mathrm{T}_{1}$ high lesions in the basal ganglia, as well as imaging of pulmonary AVFs and hepatic AVMs were reviewed retrospectively.

Our institutional review board did not require approval for this type of retrospective study. Genetic analysis was approved by the institutional review board of the National Cerebral and Cardiovascular Center, Osaka, Japan. Written informed consent was obtained from each patient or from parents of patients younger than 18 years old for all radiological examinations and genetic analysis.

The characteristics of the patients and results of the radiological examinations between HHT1 and HHT2 were compared using chi-square test. Intergroup difference of the age was compared using Student $t$-test. Statistically, $p$ value $<0.05$ was considered to be significant.

\section{Results}

Various imaging abnormalities were observed. Brain AVMs were found in 27/136 patients (19.9\%): 21/66 patients with HHT1 and 1/36 patient with HHT2. Brain AVMs were more common in HHT1 than in HHT2 ( $p<0.01)$. Multiple AVMs were found in $12 / 27$ patients $(44.4 \%)$ while single AVM was found in 15 patients $(55.6 \%)$. In HHT1, multiple AVMs were found in $9 / 20$ patients ( 1 patient with previous hemorrhage due to AVM was excluded since only post-operative MR was available). Multiple AVMs were found in 1/1 patient in HHT2. Total number of observed AVMs was 51 (mean 2.0) in 26 patients (above-mentioned 1 patient was excluded), which included 22 micro-AVMs, 19 small AVMs, 9 pial AVFs, and 1 vein of Galen aneurysmal malformation. There was no patient with AVM, of which a nidus size was more than $3 \mathrm{~cm}$. As for locations of AVMs, 35 lesions $(68.6 \%)$ were supratentorial-superficial, 6 lesions $(11.8 \%)$ were supratentorial-deep, and 9 lesions $(17.6 \%)$ were infratentorial-superficial. In 26 HHT1 patients, 18 micro-AVMs, 18 small AVMs, 7 pial AVFs, and 1 vein of Galen aneurysmal malformation were found while no micro-AVM, 1 small AVM, and 1 pial AVF were found in 1 HHT2 patient. One patient with vein of Galen aneurysmal malformation was initially treated and reported by other group. ${ }^{19)}$ Since many patients with AVMs were followed by the primary physicians after consultation to our hospital, there were no patients who presented with new cerebral hemorrhage during the study period to the best of our knowledge (Fig. 1).

Among 139 HHT patients, two symptomatic spinal AVMs $(1.4 \%)$ were observed in HHT1 and HHT2 patient each. Since the latter patient underwent surgical removal of the spinal AVM more than 40 years ago, detailed information was not available. The other spinal abnormality included cervical syringomyelia in the HHT1 patient with Chiari malformation type 1 (mother of the vein of Galen aneurysmal malformation patient), and cervical epidural AVFs in 2 patients with brain AVMs.

Seventy-three patients among 137 had pulmonary AVFs $(65.2 \%, 45 / 69$ patients with HHT1 and 6/36 patients with HHT2). Pulmonary AVFs were more common in HHT1 than in HHT2 $(p<0.01)$. Due to paradoxical embolism through pulmonary AVFs, brain infarction was observed in 17 patients $(35.6 \%$, 16/45 HHT1 patients and 0/6 HHT2 patient) and brain abscess in 3 patients $(4.1 \%, 1$ HHT1 patient and 1 HHT2 patient). Four pediatric patients under 

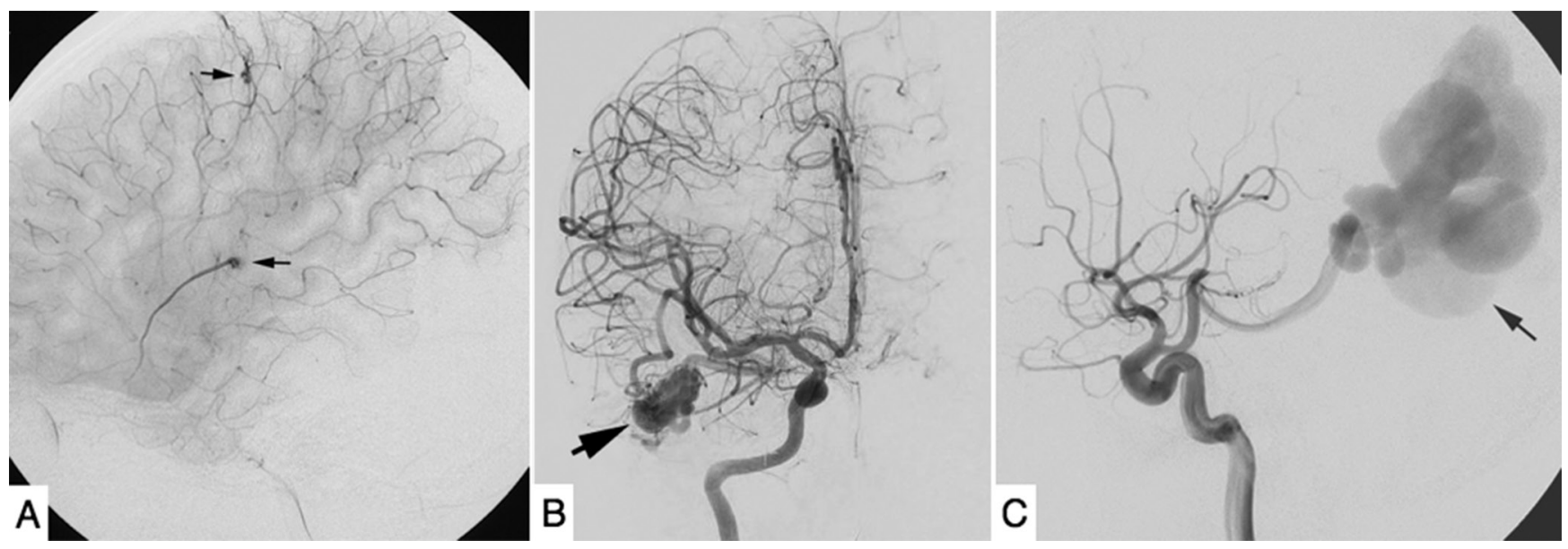

Fig. 1 Classification of AVMs in HHT. A: Micro-AVM. Size of the lesion is smaller than $1 \mathrm{~cm}$. Right internal carotid angiogram (late phase, lateral view) shows two micro-AVMs (arrows) in a 5-year-old HHT1 female. B: Small AVM with a nidus size between $1 \mathrm{~cm}$ and $3 \mathrm{~cm}$. Right internal carotid angiogram (AP view) shows a small AVM in the right temporal lobe in a 2-year-old HHT1 male. C: Pial AVF with a huge varix (arrow) in a 29-year-old HHT1 male. AP: anteroposterior, AVM: arteriovenous malformation, AVF: arteriovenous fistula, HHT: hereditary hemorrhagic telangiectasia.
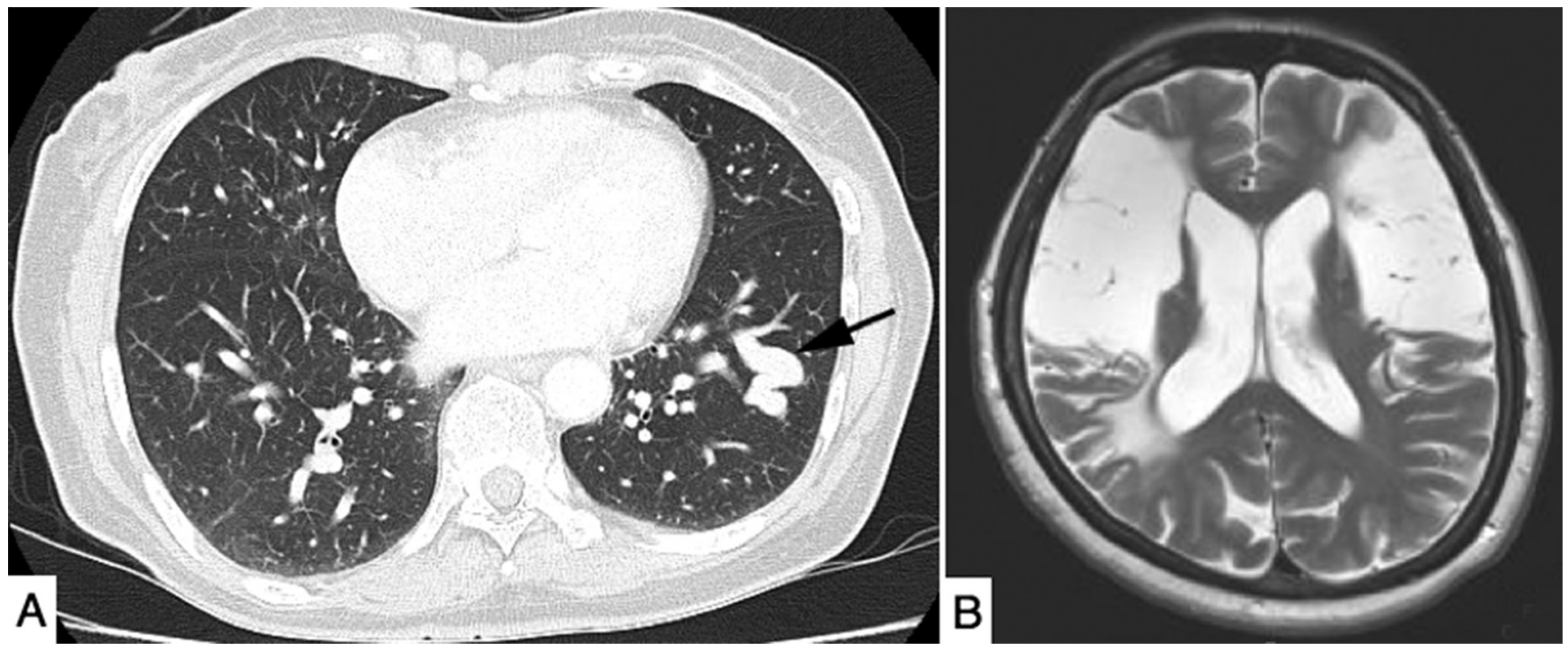

Fig. 2 Pulmonary AVF and cerebral infarction. Pulmonary AVF caused cerebral infarction twice in the 15 years' interval in a 67-year-old HHT1 female. AVF: arteriovenous fistula. A: This pulmonary arteriovenous fistula (arrow) shown on computed tomography caused paradoxical embolism. B: $T_{2}$-weighted image shows resultant cerebral infarction in bilateral middle cerebral artery territories.

18 years old among these 17 patients presented with asymptomatic brain infarction. Brain infarction was more common in HHT1 than in HHT2 $(p<0.01)$ (Figs. 2, 3).

High intensity lesions in the basal ganglia on $\mathrm{T}_{1}$-weighted images were all symmetrical, and were observed in $51 / 136$ patients $(37.5 \%, 9 / 66$ patients with HHT1 and 28/36 patients with HHT2). These high intensity lesions were more common in HHT2 patients than in HHT1 patients $(p<0.01)$. In 25 patients with high intensity lesions, serum manganese level ranged from $1.7 \mu \mathrm{g} / \mathrm{dl}$ to $6.8 \mu \mathrm{g} / \mathrm{dl}$ (mean 3.6 and standard deviation $1.3 \mu \mathrm{g} / \mathrm{dl}$ ) where normal manganese level is between $0.8 \mu \mathrm{g} / \mathrm{dl}$ and $2.5 \mu \mathrm{g} / \mathrm{dl}$. Serum manganese level in 11 patients without such high intensity lesions ranged between $1.0 \mu \mathrm{g} / \mathrm{dl}$ and $2.3 \mathrm{\mu g} / \mathrm{dl}$ (mean 1.4 and standard deviation 0.38 $\mu \mathrm{g} / \mathrm{dl}$ ). Hepatic AVMs (at least one shunt among 

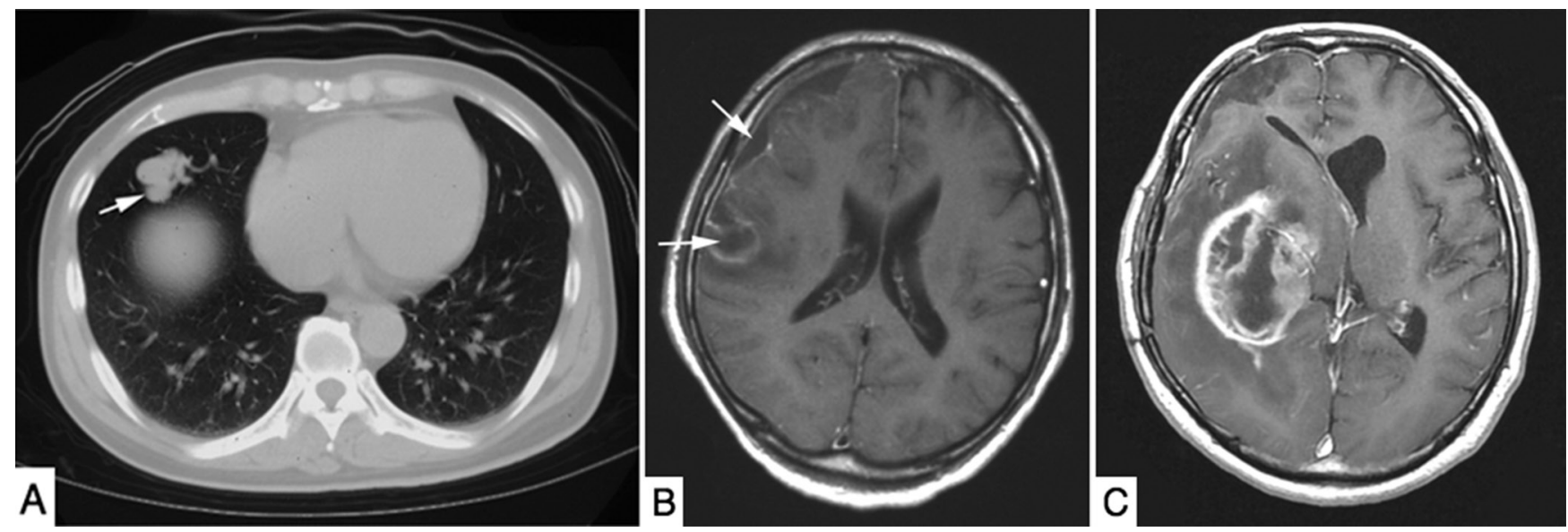

Fig. 3 Brain abscess and empyema, and brain tumor developed sequentially in a 47-year-old HHT1 male. A: Pulmonary AVF (arrow) shown on this CT is responsible for paradoxical embolism. B: Brain abscess and empyema (arrows) due to paradoxical embolism on contrast enhanced $T_{1}$-weighted image. C: Contrast enhanced $\mathrm{T}_{1}$-weighted image showing glioblastoma multiforme developed 4 years later at the location near to the prior brain abscess. AVF: arteriovenous fistula, CT: computed tomography, HHT: hereditary hemorrhagic telangiectasia.
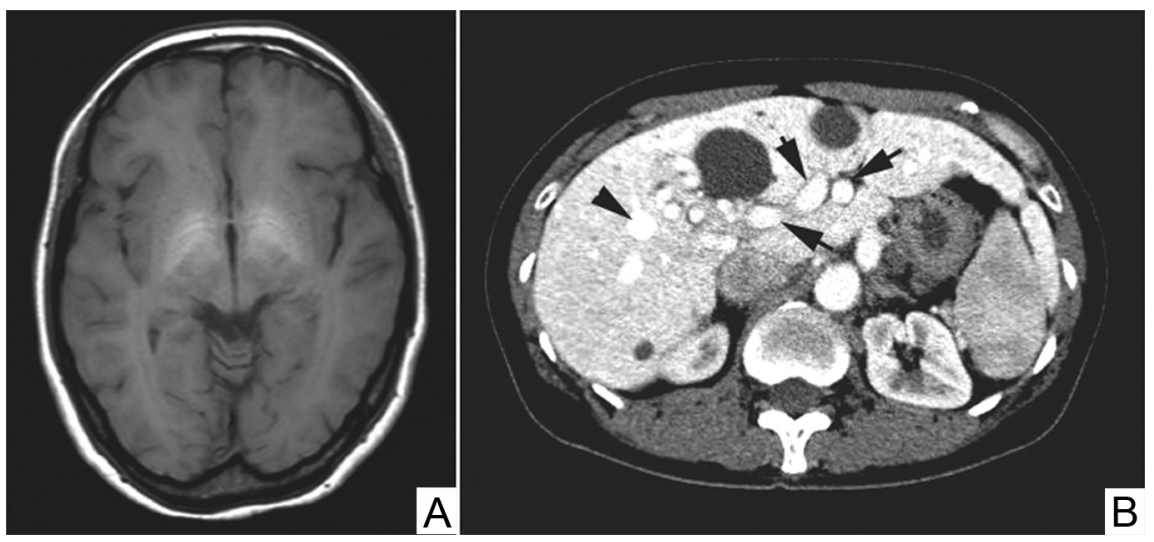

Fig. $4 \quad T_{1}$ high lesions in the basal ganglia and porto-venous shunts in a 48-year-old HHT2 female with hepatic arteriovenous malformations. A: Symmetrical high intensity lesions in the basal ganglia on $\mathrm{T}_{1}$-weighted image. Serum level of manganese was 5.9 $\mu \mathrm{g} / \mathrm{dl}$ (normal range 0.8-2.5 $\mu \mathrm{g} / \mathrm{dl}$ ). B: Dynamic computed tomography of the liver (early phase) shows large hepatic arteries (arrows) and hepatic vein (arrowhead) indicative of the arteriovenous shunts. HHT: hereditary hemorrhagic telangiectasia.

$\mathrm{AV}$, arterio-portal, and/or porto-venous shunts) were observed in 61/111 patients $(55.0 \%, 15 / 43$ patients in HHT1 and 29/34 patients in HHT2). Hepatic AVMs were more common in HHT2 than in HHT1 $(p<0.01)$ (Fig. 4).

Other imaging abnormalities included new subcortical hemorrhage not attributable to brain AVM in 1 HHT2 patient, dural AVF at the clivus in 1 patient, developmental venous anomaly in 2 patients ( 1 in HHT2 patient and 1 patient without identifiable gene mutation who also had an aberrant right subclavian artery), and cortical maldevelopment in 1 patient (Fig. 5). Cerebral aneurysms were found in 3 patients. Two aneurysms (1.5\%) were located at the common sites for cerebral aneurysms (one located at the $\mathrm{C} 2$ portion of the internal carotid artery, $3.4 \mathrm{~mm}$ in size in HHT1 patient and one at the bifurcation of the middle cerebral artery, $8.5 \mathrm{~mm}$ in size). The third HHT1 patient with a left occipital huge AVF had 1 dysplastic feeder aneurysm of the left posterior cerebral artery. Brain tumors were observed in 2 patients (astrocytoma in HHT1 patient and glioblastoma multiforme in HHT2 patient). In the latter HHT2 patient, glioblastoma developed 4 years later to successful treatment of right frontal brain abscess and empyema. Cavernous malformation was not observed in our series.

\section{Discussion}

HHT patients present with various neurological symptoms and signs, which include headache, seizure, and a variety of neurological deficits caused by brain AVM/AVFs, brain ischemia, and abscess due to paradoxical embolism through pulmonary AVFs, spinal AVMs, and hepatic AVMs.

Maher et al. ${ }^{15)}$ reported $3.7 \%$ incidence $(n=12)$ of cerebrovascular malformations among 321 HHT 


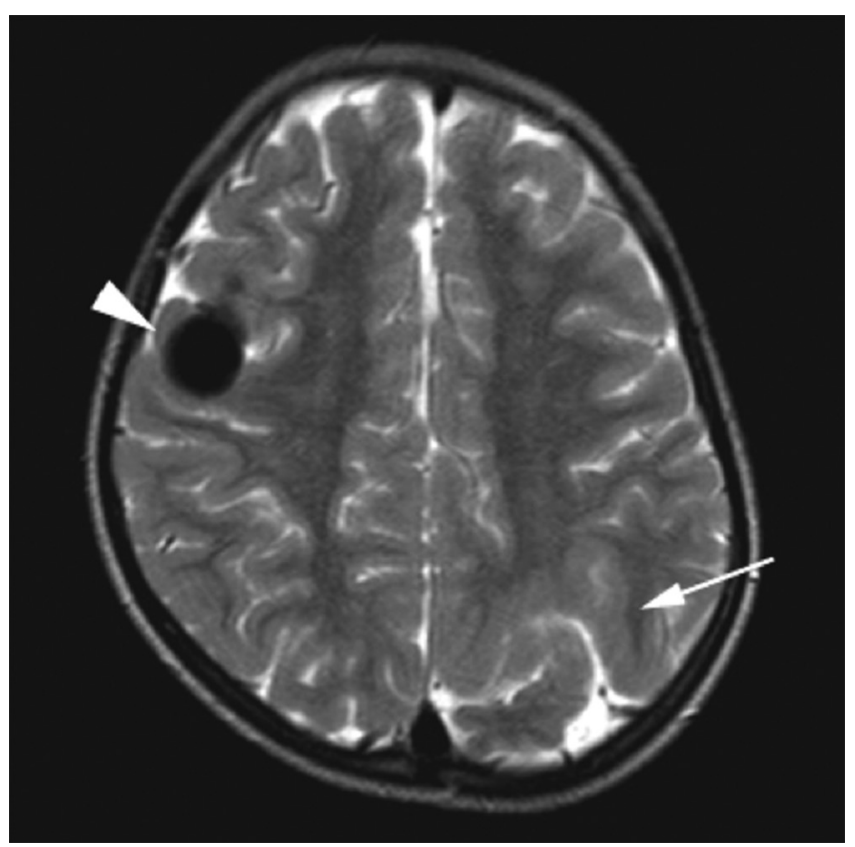

Fig. 5 Cortical maldevelopment in an 8-year-old clinically definite hereditary hemorrhagic telangiectasia female. A pial arteriovenous fistula in the right frontal lobe (arrowhead) and the cortical maldevelopment with thick gray matter in the left parietal lobe (arrow) are demonstrated on $\mathrm{T}_{2}$-weighted image.

patients, although not all patients in their study underwent examination for brain vascular malformation. They included 10 brain AVMs, 1 cavernous malformation, and 1 dural AVF. Seventy-one patients (22.1\%), who had pulmonary AVFs, developed either cerebral ischemia or brain abscess, with incidences of $29.6 \%(n=21)$ and $7.0 \%(n=5)$, respectively. Fulbright et al. ${ }^{14)}$ reported on brain MR findings in a series of 184 HHT patients. Among them, 63 cerebral vascular malformations were found in 42 patients $(22.8 \%)$, which included classic AVM ( $n=10)$, developmental venous anomaly $(n=5)$, and indeterminate vascular malformations $(\mathrm{n}=48)$. Most indeterminate vascular malformations on MRI were confirmed to be AVMs by angiography. Incidences of brain AVM (19.9\%), brain infarction (23.3\%), and brain abscess $(4.1 \%)$ among the patients with pulmonary AVFs in this series are similar to the previous reports.

It is known that clinical manifestations of HHT1 and HHT2 are different. In our series, brain AVMs were noted in $31.8 \%$ of HHT1 patients and in $2.8 \%$ of HHT2 patients, more common in HHT1 than in HHT2, $p<0.01$. Pulmonary AVMs were revealed in $64.1 \%$ of HHT1 and $16.7 \%$ of HHT2 patients, more common in HHT1 than in HHT2, $p<0.01$. Hepatic AVMs (any shunts) were observed in $34.9 \%$ of HHT1 patients and $85.3 \%$ of HHT2 patients, more common in HHT2 than in HHT1, $p<0.01$. It is reported that HHT1 is more prone to pulmonary $\mathrm{AVMs}^{8,12,13,20)}$ and brain $\mathrm{AVMs}^{12,13)}$ while HHT2 is less frequent to have pulmonary $\mathrm{AVMs}^{9)}$ and is prone to hepatic AVMs. ${ }^{12,13)}$ This was proved in Japanese HHT patients by our previous study ${ }^{21}$ and the present study again.

Angioarchitecture of brain AVMs in HHT were classified into three types, micro-AVM, small AVM, and pial AVF. ${ }^{18)}$ Capillary telangiectasia is reported to be associated with HHT. ${ }^{17)}$ Difference between micro-AVM and capillary telangiectasia in HHT is not well defined. ${ }^{18,22)}$ We believe that it is simply the difference of the transit time in the lesion, i.e., degree of AV shunting, where micro-AVM has a slow AV shunt and capillary telangiectasia has extremely slow AV shunt. This phenomenon is observed in cutaneous telangiectases in HHT. ${ }^{23)}$ In this study, we found 51 brain AVMs, which included 22 micro-AVMs, 19 small AVMs, 9 pial AVFs, and 1 vein of Galen aneurysmal malformation. Multiplicity in our series was $44.4 \%$, which is similar to the result of $39 \%$ reported by Bharatha et al., ${ }^{16)}$ who concluded that multiplicity of brain AVMs is highly predictive of the diagnosis of HHT. ${ }^{16)}$ When discussing the size of the AVMs, pial AVFs should be evaluated separately since simple direct AV shunts often have large varices $>3 \mathrm{~cm}$ and their treatments are different from small AVMs with nidi and micro-AVMs. In our series, most brain AVMs were small (80.4\%, micro-AVM + small AVM $<3 \mathrm{~cm})$, superficial in location (86.2\%), and multiple (44.4\%). This result is consistent with the previous report that brain AVMs in HHT show a trend toward small size, superficial location, and multiplicity. ${ }^{16)}$

It is not clear whether cerebral aneurysms are related to HHT. Incidences of the unruptured cerebral aneurysms of $2.4 \%$ reported by Woodall et al. ${ }^{17)}$ and $1.5 \%$ in our series is not higher than the common incidence of $1-2 \%$ among healthy adults. ${ }^{24)}$ Since the pathological changes in HHT predominantly occur in the capillo-venous side of the vasculature, ${ }^{23,25)}$ we believe that aneurysmal formation at the common sites in the circle of Willis is fortuitous. Flow-related aneurysmal formation in association with high-flow AVM/AVF is a possibility, which was noted in 1 huge pial AVF patient in our series.

Developmental venous anomaly is observed in 2 HHT patients in our series. This lesion is thought to be an extreme anatomical variant, with normal venous drainage, ${ }^{26)}$ which occurs in $2.5-3.0 \%$ of the population. ${ }^{27}$ Although pathogenesis of this lesion might be related to HHT, incidences of developmental venous anomaly of $4.3 \%$ reported 
by Woodall et al. ${ }^{17)}$ and $1.5 \%$ in our series are not high enough to conclude strong relationship of this vascular variants and HHT. Presence of cervical epidural AVFs in 2 HHT patients and dural AVF at the clivus in 1 patient could be related to HHT. It is not clear that HHT contributes to the pathogenesis of brain tumors. It may be also fortuitous. Interestingly, glioblastoma multiforme developed at the same location where the prior brain abscess had observed in 1 HHT1 patient.

Cortical maldevelopment was observed in 1 patient in our series. Bergerot et al. reported such cortical maldevelopments in 13/162 HHT patients (8.0\%) (Malformations of cortical development and brain vessels in patients with hereditary haemorrhagic telangiectasia, presented in 10th International Hereditary Hemorrhagic Telangiectasia Scientific Conference June 12th-15th, 2013 Cork, Ireland). Twelve of them were polymicrogyria, predominantly observed in perisylvian areas. The remaining 1 patient had occipital dysplasia. Although it remains unclear that cortical maldevelopment is related to HHT, further accumulation of clinical data of such cases is required.

Hepatic involvement in HHT consists of intrahepatic vascular malformations, which include AV, artertio-portal, and/or porto-venous shunts. ${ }^{28)} \mathrm{T}_{1}$ high intensity lesions in the basal ganglia, especially in the globus pallidus, are symmetrically located and they may extend to the cerebral peduncle. These high intensity lesions are caused by the deposition of paramagnetic substance of manganese. ${ }^{29)}$ Accumulation of manganese in the basal ganglia is the result of bypassing serum manganese through the liver by porto-venous shunts in HHT. Although commonly observed in our series (37.5\%), this has been ignored in most of MRI studies of the large series. Serum level of manganese among them (mean $3.6 \mu \mathrm{g} / \mathrm{dl}$ ) was higher than normal range $(0.8-2.5 \mu \mathrm{g} / \mathrm{dl})$. Our result that $\mathrm{T}_{1}$ high lesions were more common in HHT2 than in HHT1 $(p<0.01)$ is consistent with the fact that hepatic involvement is more common in HHT2 than in HHT1. It is postulated that the concentration of manganese to produce $\mathrm{T}_{1}$ high lesions is lower than the threshold required to cause hepatic symptoms clinically. ${ }^{29)}$

In conclusion, HHT patients present with a variety of neuroradiological manifestations, including brain AVM/Fs, brain infarctions, brain abscesses, and $\mathrm{T}_{1}$ high lesions in the basal ganglia, which are substantial causes of morbid-mortality in HHT.

\section{Conflicts of Interest Disclosure}

None.

Neurol Med Chir (Tokyo) 55, June, 2015

\section{References}

1) Kjeldsen $\mathrm{AD}$, Vase P, Green A: Hereditary haemorrhagic telangiectasia: a population-based study of prevalence and mortality in Danish patients. J Intern Med 245: 31-39, 1999

2) Dakeishi M, Shioya T, Wada Y, Shindo T, Otaka K, Manabe M, Nozaki J, Inoue S, Koizumi A: Genetic epidemiology of hereditary hemorrhagic telangiectasia in a local community in the northern part of Japan. Hum Mutat 19: 140-148, 2002

3) Plauchu H, de Chadarévian JP, Bideau A, Robert JM: Age-related clinical profile of hereditary hemorrhagic telangiectasia in an epidemiologically recruited population. Am J Med Genet 32: 291-297, 1989

4) Guttmacher AE, Marchuk DA, White RI Jr: Hereditary hemorrhagic telangiectasia. $N$ Eng J Med 333: 918-924, 1995

5) Shovlin CL, Guttmacher AE, Buscarini E, Faughnan ME, Hyland RH, Westermann CJ, Kjeldsen AD, Plauchu $\mathrm{H}$ : Diagnostic criteria for hereditary hemorrhagic telangiectasia (Rendu-Osler-Weber syndrome). Am J Med Genet 91: 66-67, 2000

6) McDonald MT, Papenberg KA, Ghosh S, Glatfelter AA, Biesecker BB, Helmbold EA, Markel DS, Zolotor A, McKinnon WC, Vanderstoep JL: A disease locus for hereditary haemorrhagic telangiectasia maps to chromosome 9q33-34. Nat Genet 6: 197-204, 1994

7) Shovlin CL, Hughes JM, Tuddenham EG, Temperley I, Perembelon YF, Scott J, Seidman CE, Seidman JG: A gene for hereditary haemorrhagic telangiectasia maps to chromosome 9q3. Nat Genet 6: 205-209, 1994

8) McAllister KA, Grogg KM, Johnson DW, Gallione CJ, Baldwin MA, Jackson CE, Helmbold EA, Markel DS, McKinnon WC, Murrell J: Endoglin, a TGF-beta binding protein of endothelial cells, is the gene for hereditary haemorrhagic telangiectasia type 1. Nat Genet 8: 345-351, 1994

9) Johnson DW, Berg JN, Gallione CJ, McAllister KA, Warner JP, Helmbold EA, Markel DS, Jackson CE, Porteous ME, Marchuk DA: A second locus for hereditary hemorrhagic telangiectasia maps to chromosome 12. Genome Res 5: 21-28, 1995

10) Vincent P, Plauchu H, Hazan J, Fauré S, Weissenbach J, Godet J: A third locus for hereditary haemorrhagic telangiectasia maps to chromosome 12q. Hum Mol Genet 4: 945-949, 1995

11) Gallione CJ, Repetto GM, Legius E, Rustgi AK, Schelley SL, Tejpar S, Mitchell G, Drouin E, Westermann CJ, Marchuk DA: A combined syndrome of juvenile polyposis and hereditary haemorrhagic telangiectasia associated with mutations in MADH4 (SMAD4). Lancet 363: 852-859, 2004

12) Bayrak-Toydemir P, McDonald J, Markewitz B, Lewin S, Miller F, Chou LS, Gedge F, Tang W, Coon H, Mao R: Genotype-phenotype correlation in hereditary hemorrhagic telangiectasia: mutations and manifestations. Am J Med Genet A 140: 463-470, 2006 
13) Lesca G, Olivieri C, Burnichon N, Pagella F, Carette MF, Gilbert-Dussardier B, Goizet C, Roume J, Rabilloud M, Saurin JC, Cottin V, Honnorat J, Coulet F, Giraud S, Calender A, Danesino C, Buscarini E, Plauchu H; French-Italian-Rendu-Osler Network: Genotypephenotype correlations in hereditary hemorrhagic telangiectasia: data from the French-Italian HHT network. Genet Med 9: 14-22, 2007

14) Fulbright RK, Chaloupka JC, Putman CM, Sze GK, Merriam MM, Lee GK, Fayad PB, Awad IA, White RI: MR of hereditary hemorrhagic telangiectasia: prevalence and spectrum of cerebrovascular malformations. AJNR Am J Neuroradiol 19: 477-484, 1998

15) Maher CO, Piepgras DG, Brown RD, Friedman JA, Pollock BE: Cerebrovascular manifestations in 321 cases of hereditary hemorrhagic telangiectasia. Stroke 32: 877-882, 2001

16) Bharatha A, Faughnan ME, Kim H, Pourmohamad T, Krings T, Bayrak-Toydemir P, Pawlikowska L, McCulloch CE, Lawton MT, Dowd CF, Young WL, Terbrugge KG: Brain arteriovenous malformation multiplicity predicts the diagnosis of hereditary hemorrhagic telangiectasia: quantitative assessment. Stroke 43: 72-78, 2012

17) Woodall MN, McGettigan M, Figueroa R, Gossage JR, Alleyne CH: Cerebral vascular malformations in hereditary hemorrhagic telangiectasia. J Neurosurg 120: 87-92, 2014

18) Matsubara S, Mandzia JL, ter Brugge K, Willinsky RA, Faughnan ME, Manzia JL: Angiographic and clinical characteristics of patients with cerebral arteriovenous malformations associated with hereditary hemorrhagic telangiectasia. AJNR Am J Neuroradiol 21: 1016-1020, 2000

19) Tsutumi $Y$, Kosaki R, Itoh $Y$, Tsukamoto K, Matsuoka R, Shintani M, Nosaka S, Masaki H, Iizuka Y: Vein of Galen aneurysmal malformation associated with an endoglin gene mutation. Pediatrics 128: e1307e1310, 2011

20) Berg JN, Guttmacher AE, Marchuk DA, Porteous ME: Clinical heterogeneity in hereditary haemorrhagic telangiectasia: are pulmonary arteriovenous malformations more common in families linked to endoglin? J Med Genet 33: 256-257, 1996
21) Komiyama M, Ishiguro $T$, Yamada O, Morisaki H, Morisaki T: Hereditary hemorrhagic telangiectasia in Japanese patients. J Hum Genet 59: 37-41, 2014

22) Gross BA, Puri AS, Popp AJ, Du R: Cerebral capillary telangiectasias: a meta-analysis and review of the literature. Neurosurg Rev 36: 187-193; discussion 194, 2013

23) Braverman IM, Keh A, Jacobson BS: Ultrastructure and three-dimensional organization of the telangiectases of hereditary hemorrhagic telangiectasia. $J$ Invest Dermatol 95: 422-427, 1990

24) Brown RD, Broderick JP: Unruptured intracranial aneurysms: epidemiology, natural history, management options, and familial screening. Lancet Neurol 13: 393-404, 2014

25) Mahmoud M, Allinson KR, Zhai Z, Oakenfull R, Ghadi P, Adams RH, Fruttiger M, Arthur HM: Pathogenesis of arteriovenous malformations in the absence of endoglin. Cir Res 106: 1425-1433, 2010

26) Lasjaunias P, Burrows P, Planet C: Developmental venous anomalies (DVA): the so-called venous angioma. Neurosurg Rev 9: 233-242, 1986

27) Pereira VM, Geibprasert S, Krings T, Aurboonyawat T, Ozanne A, Toulgoat F, Pongpech S, Lasjaunias PL: Pathomechanisms of symptomatic developmental venous anomalies. Stroke 39: 3201-3215, 2008

28) Garcia-Tsao G: Liver involvement in hereditary hemorrhagic telangiectasia (HHT). J Hepatol 46: 499-507, 2007

29) Baba Y, Ohkubo K, Hamada K, Hokotate H, Nakajo M: Hyperintense basal ganglia lesions on T1-weighted images in hereditary hemorrhagic telangiectasia with hepatic involvement. J Comp Assist Tomogr 22: 976-979, 1998

Address reprint requests to: Masaki Komiyama, MD, Department of Neuro-intervention, Osaka City General Hospital, 2-13-22 Miyakojima-Hondori, Miyakojima-ku, Osaka, Osaka 543-0021, Japan. e-mail: komiyama@japan-mail.com 